Safety Analysis Information for Processing of HEU Metal

D. Riley, K. Dodson

January 10, 2008 
This document was prepared as an account of work sponsored by an agency of the United States government. Neither the United States government nor Lawrence Livermore National Security, LLC, nor any of their employees makes any warranty, expressed or implied, or assumes any legal liability or responsibility for the accuracy, completeness, or usefulness of any information, apparatus, product, or process disclosed, or represents that its use would not infringe privately owned rights. Reference herein to any specific commercial product, process, or service by trade name, trademark, manufacturer, or otherwise does not necessarily constitute or imply its endorsement, recommendation, or favoring by the United States government or Lawrence Livermore National Security, LLC. The views and opinions of authors expressed herein do not necessarily state or reflect those of the United States government or Lawrence Livermore National Security, LLC, and shall not be used for advertising or product endorsement purposes.

This work performed under the auspices of the U.S. Department of Energy by Lawrence Livermore National Laboratory under Contract DE-AC52-07NA27344. 


\section{Safety Analysis Information for Processing of HEU Metal}

Revision 0

January 7, 2008

Prepared by:

David Riley

Date

LLNL De-Inventory Engineer

Approved by:

Karen E. Dodson

$\overline{\text { Date }}$

LLNL De-Inventory Project Manager 


\section{Summary}

Lawrence Livermore National Laboratory (LLNL) is shipping Highly Enriched Uranium (HEU) metal to Savannah River Site (SRS) for future processing in H Area. This material will be stored in the SRS K-Area Material Storage (KAMS) facility until it is processed. This document is a description of how the material will be prepared for shipment and in particular, how the mass of the material is established and verified to meet criticality safety requirements in both SRS's storage and processing areas.

\section{Processing Requirements}

\section{$2.1 \mathrm{H}-$ Area Requirements}

LLNL will be preparing the material for future processing at SRS's H-Area. The HArea processing will involve charging the entire container into a dissolver. This results in the following requirements:

No aluminum in container or packaging - Aluminum is used in the H-Area dissolver to adjust the chemistry. To eliminate any impacts to the dissolver chemistry, no aluminum may be used in the processing or packaging of the HEU metal.

Maximum material content of $1.2 \mathrm{~kg}$ of ${ }^{235} \mathrm{U}$ per container - To control criticality safety mass limits, SRS requires LLNL to keep the amount of ${ }^{235} \mathrm{U}$ material in each container to less than $1.2 \mathrm{~kg}$.

Plastics limited to nylon - Materials that are added to the H-Area dissolvers must dissolve quickly to prevent the buildup of non-critical safe configurations. The dissolver chemistry will not rapidly dissolve polyvinylchloride or polyethylene bags that LLNL normally uses for the bagging out of materials from gloveboxes.

However, nylon does meet the dissolution rates required for $\mathrm{H}$-canyon processing; therefore, the bag-out bags used for removal of the HEU from LLNL glove boxes must be nylon.

\subsection{LLNL Processing Requirements}

Most of the metals to be processed have already been measured using Material Control and Accountability (MC\&A) techniques. The HEU metal is hard to measure because of the low activity of the material. Since the items are already measured, LLNL will be processing them in a manner to maintain the MC\&A control of them. The controls required to do this are included in the letter in Attachment 1 and include the following:

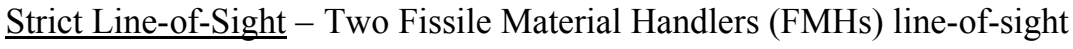
surveillance of a previously measured metal uranium item shall be maintained while the item is accessed for sizing. Items in the process of being sized shall not be left unattended unless they are placed in a container, sealed and a Tamper Indicating Device (TID) applied. See bullets 1 and 4 of the attached letter. 
Initial weight verification - The net weight of each metal item to be sized shall be verified prior to beginning the sizing process. See bullet 3 of the attached letter.

Only one item processed at a time - Only one item can be sized at a time within the same workstation. Any remaining residue from the sizing process shall be collected, weighed, and recorded in COMATS. See bullets 2 and 5 of the attached letter.

Combining items - Upon completion of the sizing of an item, containers will be filled to the agreed upon fill limit. Left over material from the sized item will be assembled with the next sized part used for packaging the next container. See bullet 5 from the attached letter.

\section{Material Preparation}

The information about the processing of each can will be documented on a datasheet. An example datasheet is included in Attachment 2.

Each item will be transferred from storage into an inert atmosphere glovebox. The initial material will be documented on the datasheet in field 1 . The material will be under twoperson visual line of sight control from the point that the TIDs on the container are broken until new TIDs are applied to the container surrounding the material. After the TID is broken, the can is opened, and the contained item is weighed. If the weight of the material is within 3 grams of the recorded net weight of the material it will be processed. If not, materials management will be contacted for further guidance.

The items will be checked visually for the presence of loose or foreign material such as beryllium, carbon, oils, or other moderators or reflectors. The weight will be adjusted on the datasheet (field 1) to reflect any materials that are removed from the part, and then if necessary, the HEU metal items will be broken or cut into pieces small enough to fit into a primary can. The primary can will be a pint paint or sealed quart can. The pint paint cans are 3.23" inner diameter (ID) and 3.43" inner height with a 2.25" opening in the top. An example of this can is Freund Model 1812. The quart can has dimensions of 4" ID x 5.4" height. This can is sometimes identified as a motor oil can. Each primary can will be limited to $1.2 \mathrm{~kg}$ of ${ }^{235} \mathrm{U}$. Multiple primary cans may be filled with material from a single (parent) item. As each primary can is filled, the mass quantity in the can will be recorded on the datasheet in field 1 . Any remaining material for the item will be placed into a separate container. The following information for the primary can will be recorded: tare weight of the primary can, net weight of the material in the primary can, the primary can gross weight, the primary can type, the primary can serial number, where and when packaged, and names of persons packaging. These values will be recorded in fields 2-9. This is the first verification point for the weight of HEU loaded into a can. The values of tare weight, net weight, gross weight, serial number, and packaging type will be entered into the COMATS system that requires two-person verification of the entry. The COMATS material splits will be performed before the next item is opened. Any small pieces will be placed into a sweeps can that will later be calcined to produce 
oxide that will be packaged into oxide cans. The remaining portion of the item can be combined with the material from the next item.

Each primary can will be bagged-out of the glovebox by using a nylon bag-out bag. This bag will be 2-mil nylon that will be heat sealed. Then it may be sealed into another 2 mil nylon bag. This bagged primary can will be placed into a secondary can that will be crimp sealed. If the primary can is a pint paint can, the secondary can could be a sealed quart or juice can. If the primary can is a sealed quart, then the secondary can will be a sealed juice can. The juice can has dimensions of 4.17" ID and 6.89" height. This is also known as a $404 \times 700$ can. This means that it is $44 / 16$ " OD and $70 / 16$ " in height. The serial number of the item will be written on the outside of the can. This is the can that is expected to be charged to the dissolver in H-Area. A standard LLNL E\&SH label will be attached to the outside of the can using tie wraps so that no adhesive residues remain on the outside of the can. The weight of the assembled system and the packaging configurations (layers of nylon and secondary container) will be documented on the datasheet in fields 10 and 11 . The weight will be compared to a maximum weight limit of 1600 grams (the calculation of this value will be explained below).

The secondary can will be placed into a gallon paint can and TIDs applied to the paint can for vault storage before packaging into the shipping container. This is so there are no residues of adhesive remaining on the outside of the quart or juice can. The gallon can information will be recorded in fields 12,13 , and 14 . The secondary can will be removed from the gallon paint can at the time of shipping preparation.

The datasheet will be submitted to a project engineer for verification. The engineer will verify that the datasheet is complete and that the recorded weights are within required weight limits for the package. This weight limit is no more than 1600 grams for any packaging configuration (see Section 3.1). This acts as a third verification that there is no over batch.

After the engineer has verified and approved the datasheet, the item meets the requirements for placement into a DOT $6 \mathrm{M}$ shipping package. The material will be shipped in a $2 \mathrm{R}$ within the DOT $6 \mathrm{M}$ shipping package. The $2 \mathrm{R}$ cavity has the dimensions of $53 / 64$ ID by 23" height. Each item will be transferred from storage to the packaging area. The TIDs will be removed form the gallon can for retrieval of the secondary can. The secondary can will be weighed and two individuals will verify that the weight of matches the recorded weight. If the weight does not agree within 30 grams of the recorded weight then the loading of that item will be stopped until the weight difference is resolved. This is a fourth validation of the correct loading of the cans. The can with the tie wrapped label will be placed into the $2 \mathrm{R}$. The height of the $2 \mathrm{R}$ cavity limits the number of containers per drum to three [3] for the juice can and four [4] for the quart can. Assuming the maximum loading of $1.2 \mathrm{~kg}{ }^{235} \mathrm{U} /$ container, then four quart cans would result in a maximum of $4.8 \mathrm{~kg}^{235} \mathrm{U}$ in the DOT $6 \mathrm{M}$ shipping package. This is conservative because the material is not pure ${ }^{235} \mathrm{U}$ and all of the cans will not be filled to $1.2 \mathrm{~kg}{ }^{235} \mathrm{U}$. The $6 \mathrm{M}$ containers will then be closed and staged for shipping. 


\subsection{Calculation of expected weight and maximum load limit.}

The weights of the pint paint cans, sealed quart, nylon bags, sealed juice cans, tie wraps, labels, gallon cans and TID labels were measured and are included in Attachment 3. This information was used to calculate an expected range of weights for each item using three standard deviations to give a $99.6 \%$ certainty in the weights of the items.

The estimated weights of the cans were determined by including the weight of the following items:

HEU metal [Maximum of $1.2 \mathrm{~kg}$ of ${ }^{235} \mathrm{U}$ ], Primary can [Pint paint can or sealed quart can],

Bag-out bag(s) [single or double layer nylon bag-out bag, secondary nylon bag],

Secondary cans [Sealed quart or juice for pint paint primary can

or sealed juice for sealed quart primary paint can],

Label with backing [Will not stick label to can], and

Two Tie wraps.

There are three packaging configurations that can be assembled from these items. They are shown in the following table:

\begin{tabular}{|c|l|l|}
\hline Configuration & Primary Container & Secondary Container \\
\hline \hline 1 & Pint Paint & Sealed Quart \\
\hline 2 & Pint Paint & Sealed Juice \\
\hline 3 & Sealed Quart & Sealed Juice \\
\hline
\end{tabular}

The ranges of weights for each of these configurations were calculated using the information from Attachment 3. Taking the maximum weight of each item in a packaging configuration results in the maximum weights for full cans ranging from 1415 to 1576 grams (Table 1). Setting the upper weight limit for the assembled can configuration at 1600 grams will bound the weight for the heaviest package. The other end of the range would be if the packaging was at the minimum weight. If this were the case, there would be a maximum over batch of 211 grams per HEU can (see example at Table 1). If there were four of these cans loaded into a DOT 6M shipping package, the maximum over batch would be 844 grams.

\section{Safety Input}

The DOT 6M shipping package will be stored in KAMS. The KAMS Authorization Basis assumes that a criticality is extremely unlikely. Therefore, the probability of criticality of these containers is evaluated. The evaluated criticality restrictions are for the presence of moderators or reflectors in the container and the probability of over batching the drums. 


\subsection{Moderator in the containers}

Each item to be processed will be brought into a glovebox, opened, size reduced, and packaged. Therefore, each item will be visually inspected. During the visual inspection, any foreign materials such as plastics, graphite, beryllium, oil, or other moderators or reflectors will be removed.

No additional moderators or reflectors will be added to the inside of the primary can. The primary can is bagged out of a glove box; therefore, there will be some moderator (i.e., bag-out bag) on the outside of the primary can. These moderators may include the nylon bag-out bag(s), the nylon secondary bag, the plastic tie wraps, and/or the paper label.

\subsection{Over Batch Probability}

Based on the above example, the following errors could occur that might result in the DOT 6M shipping package being over batched:

- Incorrect isotopic measurement of the material,

- Too much material being loaded into a container,

- Selecting the wrong item for packaging, and

- Placing more than 4 secondary cans in a 9975 shipping container.

Each of these errors is analyzed below.

\subsubsection{Incorrect measurement of the item}

LLNL conservatively assumes that the entire material weight is pure ${ }^{235} \mathrm{U}$. That is MC\&A measurements of the isotopics are not considered for packaging purposes. Therefore, there is no probability of failure in the isotopic measurements.

\subsubsection{Selecting an over batched item to ship.}

\subsubsection{Postulated error}

An over batching error would be caused by selecting an incorrect item to be shipped or packaging an over batched container. The selection of an incorrect item could occur by the operator packing item A when he should have packaged item B. Because of the unique way that the HEU metal items are packaged it would be impossible for the packager to select a non-HEU metal item to be packaged. These are the only containers in the vault that are juice or quart cans with tie wraps holding the label on in a gallon can with a TID. The gallon cans cannot fit into the $2 \mathrm{R}$, so the person packaging the $2 \mathrm{R}$ will not accidentally package a gallon can that contains something besides HEU metal. When the gallon can is opened, the packager will see that the label is attached with tie wraps. Therefore, it is impossible for the operator to load a non-HEU metal container into the $2 \mathrm{R}$ containers. The packager can place the wrong quart or juice can of HEU meal into the $2 \mathrm{R}$, but it would not be a non-HEU container. 
The preparation of the quart or juice cans is controlled such that the probability of over batching them is discussed below.

\subsubsection{Description of System}

There are a number of controls in place to ensure that the proper material is packaged and transferred. These controls have been instituted for the purposes of criticality and MC\&A control at LLNL. They also ensure that individual cans and shipping packages are not over batched. Many of these controls are administrative; therefore, the probability of an error is determined by human error rates. These controls include:

\section{Calibration checks of scales each day they are used.}

Each day that a scale is used for MC\&A measurements, the calibration of the scales are checked using different calibrated weights by the FMHs. This insures that the weighing is accurate.

\section{LLNL Move Procedure}

The Move Procedure requires the shipper and receiver to both understand what is being transferred. Therefore, if the receiver gets a different item than expected, he will terminate the transfer and investigate the cause.

\section{COMATS MC\&A Data Base}

The use of the COMATS system requires two individuals to verify any modifications of materials. This provides a double check of all operations including material balances.

\subsubsection{Failure Probability}

The human error probabilities associated with material movements were developed as part of the B332 Documented Safety Analysis (Reference 2, Appendix B). The probabilities used were:

\begin{tabular}{|l|c|}
\hline \multicolumn{1}{|c|}{ Event } & Failure Probability \\
\hline \hline Failure of administrative control (nominal value) & $5 \times 10^{-3}$ \\
\hline $\begin{array}{l}\text { Checker (or second operator) verification error } \\
\text { (nominal value) }\end{array}$ & $1 \times 10^{-1}$ \\
\hline
\end{tabular}

\subsubsection{Probability of Error}

The transfer of an over batch item to SRS requires the creation of that item and then the packaging of that over batch item into the shipping package. The fault tree for calculating the probability of creating and packaging an over batch item is shown in Figures 1, 2, and 3. Material is moved into a glovebox, size reduced and placed into primary can(s). Two operators verify the amount of material placed in each primary can and the overall material balance. This is represented by events 1, 2, 3 with both FMHs miss-reading the scale at a probability of $5.0 \times 10^{-4}$. There could also be a data entry error that could also generate an over batched convenience can 
(events 4, 5 and 6). These result in a failure probability of $5.0 \times 10^{-4}$.

Either of these errors could result in an over batched primary can.

Therefore, the probabilities are added to give $1.0 \times 10^{-3}$ (event 7 ). Then the primary can is bagged out and placed into a secondary can where it is weighed again and checked versus the weight limit. To generate an over batched can requires that when the FMHs check the weight of the secondary can, the same kind of scale reading-reading failure occurs, with a failure probability of $5.0 \times 10^{-4}$ (events $8,9,10$ ). The can is next transferred to a storage vault. The failure probability of sending the over batch can to the vault is $5.0 \times 10^{-7}$ (event 11).

After the items are packaged, the datasheet is then sent to a project engineer for review. The review involves checking that the sheet is appropriately filled out and to check that the weight of the finished can is consistent with the weights of the parts that went into making the cans in addition to verifying that the overall weight is less than 1600 grams. The engineer authorizes the can to be released for packaging for shipment. This has a probability of failure of $5 \times 10^{-3}$ (event 12). This results in the failure probability that an over batch can is released for packaging of $2.5 \mathrm{x}$ $10^{-9}$ (event 13)

Prior to putting the secondary can into the $2 \mathrm{R}$ pipe in the DOT $6 \mathrm{M}$ shipping package, it is weighed again to verify the weight. The probability of failure for this is the same as for the initial weighing (events 14,15 , and 16). Therefore, the probability that an over batched can will get packaged has an overall probability of failure of $1.25 \times 10^{-12}$ (Event 17). There is a maximum of four items that can be placed into the $2 R$ container. Any of these items can be over batched (events 18. 19, 20, and 21 ), therefore the probability of these happening are added resulting in a probability of an over batched $6 \mathrm{M}$ as $5 \times 10^{-12}$ (event 22).

\subsubsection{Placing too many cans into the shipping container.}

\subsubsection{Postulated Error}

It has been shown that it is incredible to send more than $4.8 \mathrm{~kg}$ of HEU if the drum is limited to four cans. It is conceivable that the shipping container could be over batched if more than four cans were inserted into it.

\subsubsection{Description of System}

The inner height of a $2 \mathrm{R}$ pipe is 23 " long. To achieve more then four items in the pipe would require that the length of the inserted material would have to be less than $23 " / 5=4.6 "$. The only cans that are allowed in the LLNL Plutonium Facility with height less than 4.6" will not hold a pint paint can based on height and/or diameter. Therefore, it is impossible to load more than four cans into the $2 \mathrm{R}$. The pint paint cans are less than 
4.6" tall, but to remove the pint paint cans out of the glovebox requires a bag-out operation. A bagged out can without a secondary can is not allowed in the vault and would not be packaged for shipping because the packager would see the bag-out bag as the final barrier and reject it for packaging. Therefore it is impossible for there to be more than 4 cans in the $6 \mathrm{M}$ drum.

\section{Results}

This paper showed that there are sufficient controls at LLNL to ensure that the maximum credible (i.e. frequency $>1 \mathrm{E}-6$ ) over batch (process upset condition) for the loaded $6 \mathrm{M}$ shipping container is less than $1.0 \mathrm{~kg}$ of fissile materials. The controls assure that:

1) The probability that an over batched $6 \mathrm{M}$ drum containing greater than $5.8 \mathrm{~kg}$ of fissile materials was incredible, and

2) The probability of more than four cans being loaded into a DOT 6M shipping package was incredible.

\section{References}

1) B332 FSP, Defense and Nuclear Technologies Directorate Plutonium Facility Building 332 Facility Safety Plan, FSP-332-07, April 2007, Lawrence

Livermore national Laboratory

2) B332 Documented Safety Analysis, Defense and Nuclear Technologies Directorate Plutonium Facility - Building 332 Documented Safety Analysis, UCRL-AR-119434-05, December 2005, Lawrence Livermore national Laboratory 


\begin{tabular}{|c|c|c|c|c|c|c|}
\hline \multicolumn{7}{|c|}{ Attachment 3, Table 1} \\
\hline Configuration & $\begin{array}{c}\text { Primary } \\
\text { Container }\end{array}$ & $\begin{array}{l}\text { Secondary } \\
\text { Container }\end{array}$ & $\begin{array}{l}\text { Maximum HEU } \\
\text { Weight (grams) }\end{array}$ & $\begin{array}{c}\text { Packaging } \\
\text { Weight Range } \\
\text { (grams) } \\
\end{array}$ & $\begin{array}{c}\text { Maximum Package } \\
+ \text { HEU Weight } \\
\text { (grams) }\end{array}$ & $\begin{array}{c}\text { Potential } \\
\text { maximum } \\
\text { over } \\
1600 \mathrm{~g}^{*} \\
\end{array}$ \\
\hline 1 & Paint Pint & Sealed Quart & 1200.0 & 188.8 to 214.7 & 1414.7 & $211.2 \mathrm{~g}$ \\
\hline 2 & Paint Pint & Sealed Juice & 1200.0 & 324.7 to 347.5 & 1547.5 & 75.3 \\
\hline 3 & Sealed Quart & Sealed Juice & 1200.0 & 347.6 to 376.2 & 1576.2 & 52.4 \\
\hline
\end{tabular}

*Example calculation for Configuration 1: Assuming maximum HEU $(1200 \mathrm{~g})$ plus weight of smallest packaging $(188.8 \mathrm{~g})=1388.8)$ then the maximum over batch for this example would be $211.2 \mathrm{~g}(1600 \mathrm{~g}-1388.8 \mathrm{~g})$ 
Figure 1: HEU Metal Packaging Fault Tree

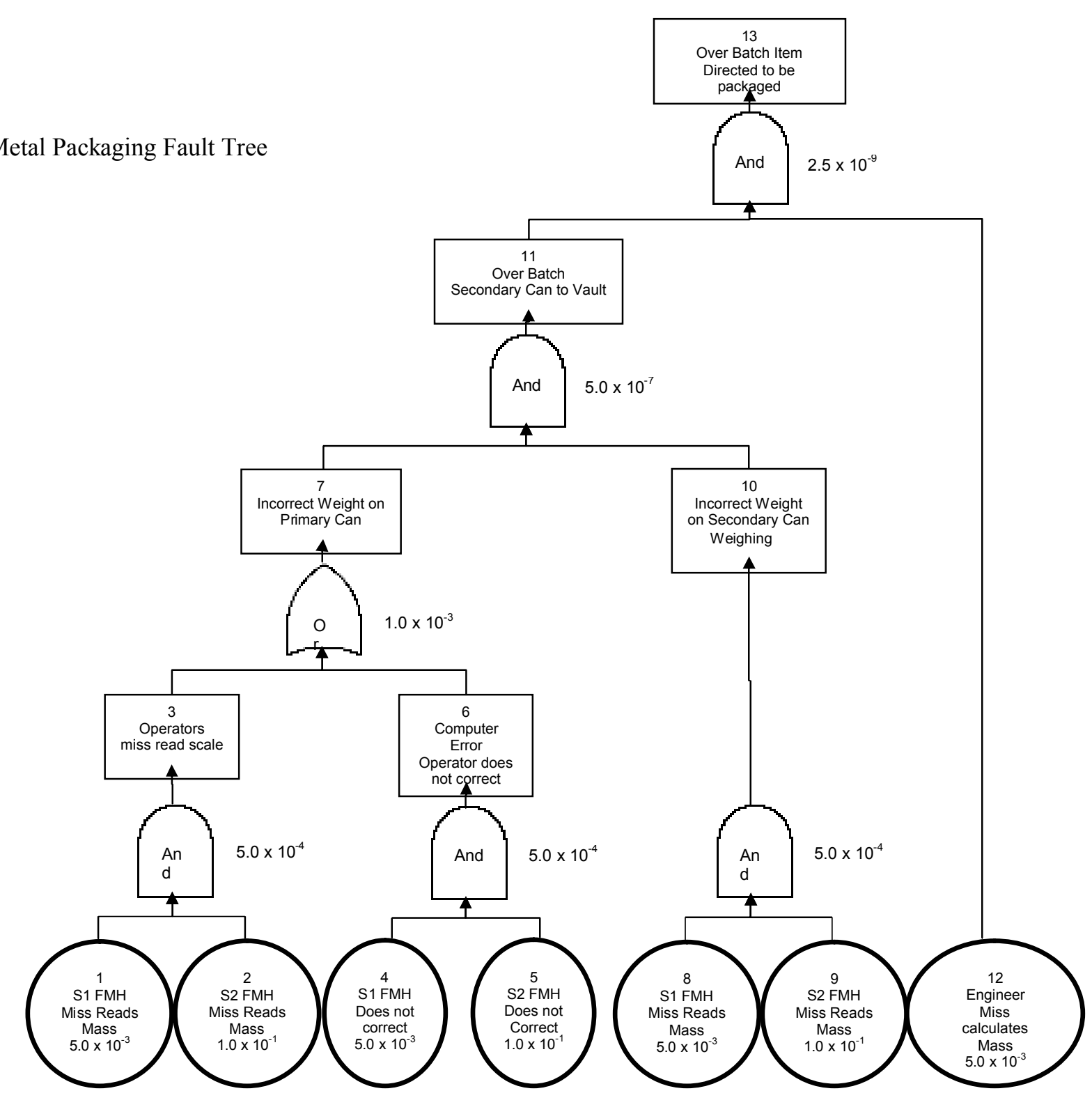


Figure 2: HEU Fault Tree (Continued)

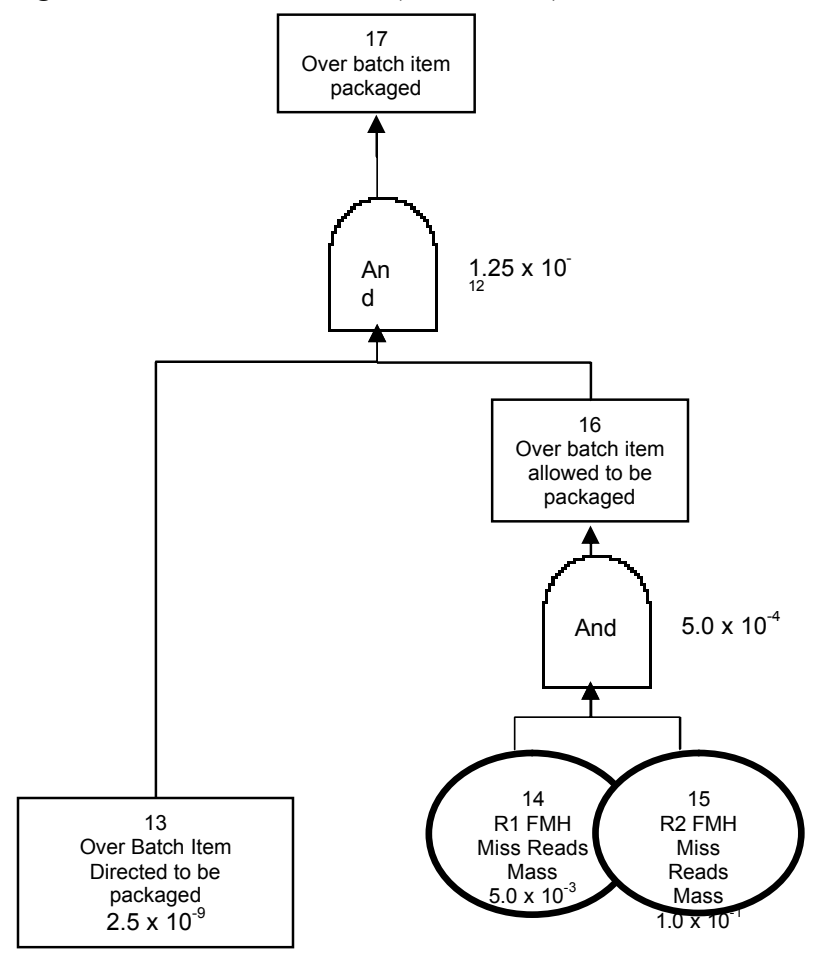

Figure 3: HEU Fault Tree (Continued)

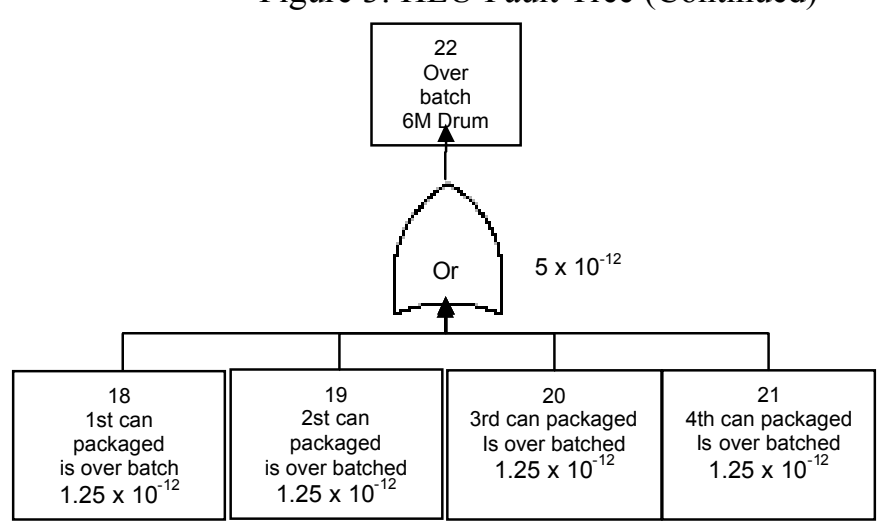




\section{Attachment 1: Letter \\ Formatted: Font: 22 pt, \\ Formatted: Centered \\ Formatted: Indent: Left:}




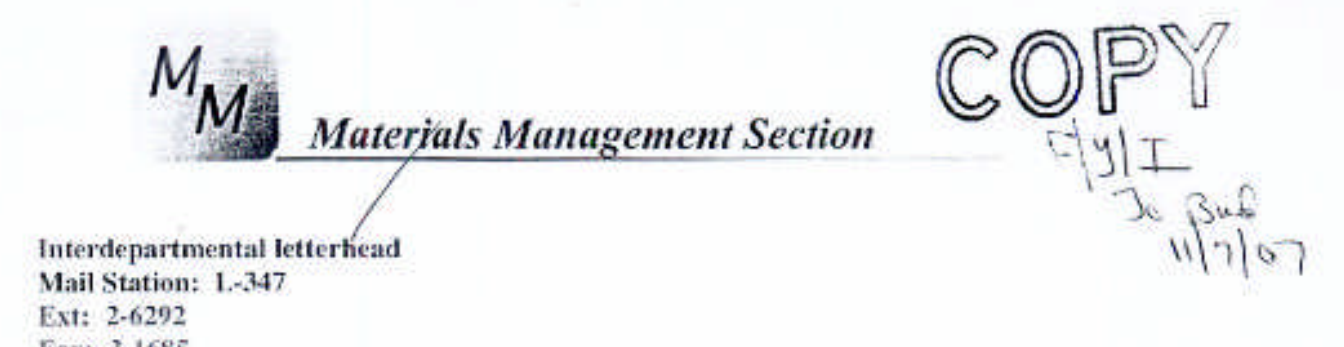

Fax: 3-1685

November 7,2007

MMS07.044

TO:

Bud Marsh, National Nuclear Security Administration

FROM: Michael K. Sheaffer, Materials Management Section

\section{SUBJECT: Control of Measured Uranium Items During Sizing}

A number of enriched uranium items are scheduled for shipment as part of the LLNL de-inventory activities. Many items will require a reduction in their physical size in order to fit in primary containers. All have been previously quantitatively measured. As sizing alters only the shape of the item and not the physical form, net weights will be used to establish new book values for the items sized.

Enhanced material controls will be established to protect against single person access to the item and the possibility of substitution during sizing. These controls may be used for future sizing of other materials as the de-inventory project continues. These are:

- Strict line-of-sight two-person surveillance of a previously measured metal uranium item shall be maintained while the item is accessed for sizing. Both individuals shall be adequately knowledgcabie and in a position to identify inappropriate actions of the other.

- Only one item can be sized at a time within the same workstation. Containers with other items to be sized may be staged in the workstation, but their TIDs cannot be removed and they shall remain sealed until completion of sizing of the current item.

- Fin in in itht of each metal item to be sized shall be verified prior to beginning Dim innt, process. Anv difference between the verified weight and the immediately reported to the Materials Management Section and sizing will be stopped until the difference is resolved.

- Items in the process of being sized shall not be Jeft unattended unless they are placed in a container, sealed, and a TID applied. 


\section{M

- Upon completion of the sizing of an item, containers will be filled to the agreed upon fill limit ( $E U$ limit). Left over material from the sized item will be assembled with the next sized part used for packaging the next container. A new net weight for the item shall be established and recorded in COMA'IS. Any remaining residue from the sizing process shall be collected, weighed, and recorded in COMATS.

- The removal of an applied tamper indicating device, application of a new tamper indicating device, or the packaging of material into a container that is intrinsically tamper indicating and the identification of the persons performing these activities shall be documented in COMATS, consistent with established procedures.

Any questions regarding this process should be addressed to Todd Taylor (3-5131).

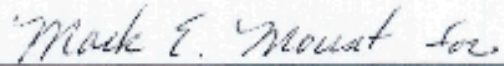

Micheal K. Sheaffer

Section Leader

Materials Management Section 
Attachment 2: Datasheet

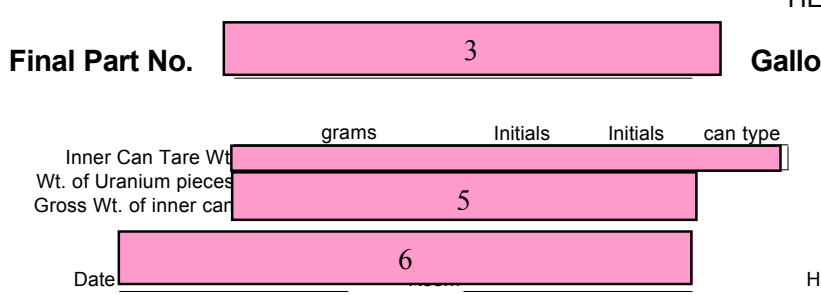

HEU Processing Data Sheet

Gallon TID $\quad$ Shipping TID

Assembly and Split Information

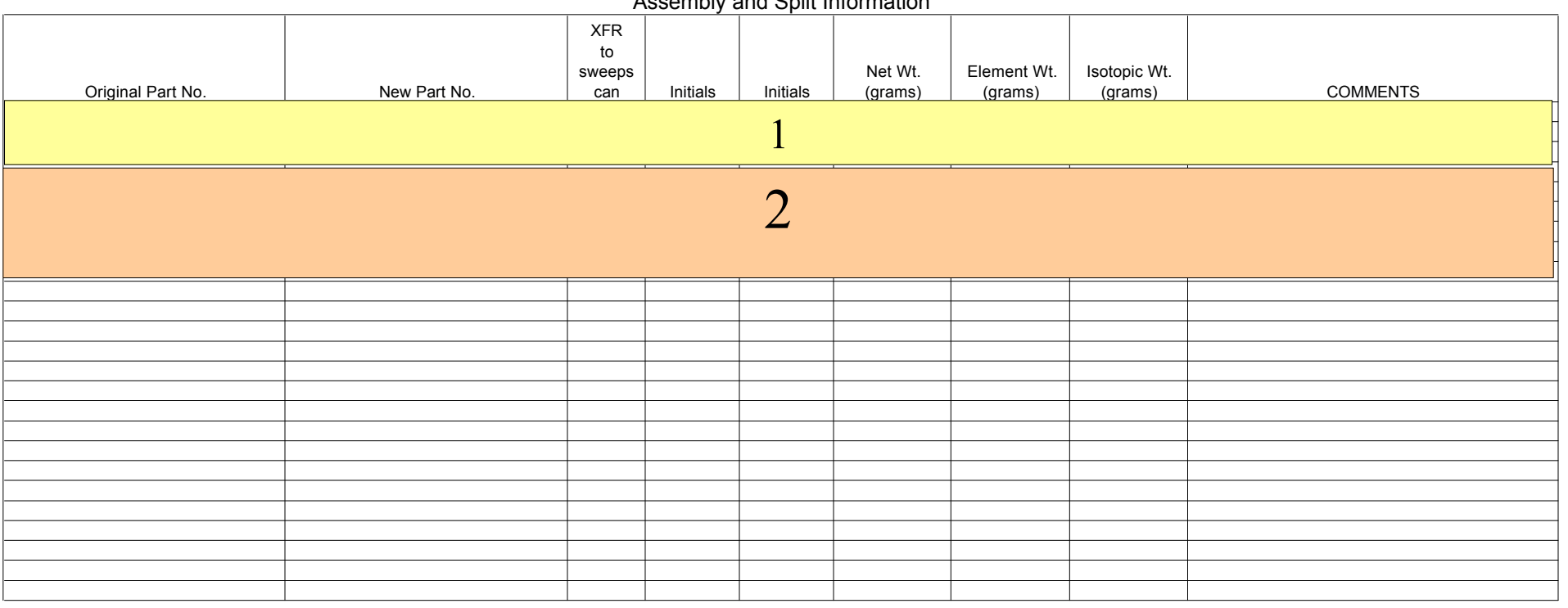

Can type: $P P=$ pint paint; $S Q=$ sealed quart; $S J$ = sealed juice. Note: All cans are made of carbon steel.

$$
\begin{array}{r|r|}
\begin{array}{r}
\text { Balance Location (glovebox) } \\
\text { Balance Location (room) }
\end{array} \\
\hline
\end{array}
$$

Data sheet verification by:

Name:

Date: 
Attachment 3: Weight Data

\begin{tabular}{|c|c|c|c|c|c|c|c|}
\hline & $\begin{array}{c}\text { Pint } \\
\text { Paint } \\
\text { Can }(g)\end{array}$ & $\begin{array}{l}\text { Sealed } \\
\text { Quart } \\
(\mathrm{g})\end{array}$ & $\begin{array}{l}\text { Sealed } \\
\text { Juice } \\
\text { (g) }\end{array}$ & $\begin{array}{c}\text { Paper } \\
\text { Label Still } \\
\text { on backing } \\
\text { (g) }\end{array}$ & $\begin{array}{c}\text { Tie wraps } \\
\text { (14" long) } \\
\text { (g) }\end{array}$ & $\begin{array}{c}\text { Gallon } \\
\text { Cans } \\
\text { without } \\
\text { Ears }(\mathrm{g})\end{array}$ & $\begin{array}{c}2 \text { TIDs } \\
\text { (with } \\
\text { Backing) } \\
\text { (g) }\end{array}$ \\
\hline & 78.9 & 101.4 & 238.8 & 5.4 & 2.5 & 332.3 & 1.9 \\
\hline & 78.7 & 105.3 & 236.1 & 5.3 & 2.4 & 329.7 & 2.1 \\
\hline & 78.2 & 103.3 & 238.2 & 5.7 & 2.4 & 333.5 & \\
\hline & 77.3 & 104.2 & 237.9 & 5.5 & 2.4 & & \\
\hline & 77.2 & & 238.6 & 5.4 & 2.4 & & \\
\hline & 77.4 & & 238.2 & 5.5 & 2.4 & & \\
\hline & 77.1 & & 236.5 & 5.4 & 2.4 & & \\
\hline & 77.4 & & 236.9 & 5.5 & 2.4 & & \\
\hline & 76.9 & & 238.9 & 5.5 & 2.4 & & \\
\hline & 79.2 & & 238.1 & 5.5 & 2.4 & & \\
\hline & 78.1 & & 236.8 & 5.5 & 2.3 & & \\
\hline & 77.3 & & 237.7 & 5.6 & 2.4 & & \\
\hline & 77.2 & & 237.5 & 5.5 & 2.4 & & \\
\hline & 77.6 & & 237.4 & 5.5 & 2.4 & & \\
\hline & 77.2 & & 238.9 & & 2.4 & & \\
\hline & 77.6 & & 239.1 & & 2.4 & & \\
\hline & 77.5 & & 237.2 & & 2.5 & & \\
\hline & 78.7 & & 237.2 & & 2.4 & & \\
\hline & 77.2 & & 236.5 & & 2.4 & & \\
\hline & 77.3 & & 240 & & 2.4 & & \\
\hline & 78 & & 241 & & & & \\
\hline & 77.6 & & 237.7 & & & & \\
\hline & 78.9 & & 236.3 & & & & \\
\hline & 77.3 & & 238.8 & & & & \\
\hline & 77.3 & & 237.8 & & & & \\
\hline & 78.9 & & 238.7 & & & & \\
\hline & & & 237.3 & & & & \\
\hline & & & & & & & \\
\hline Average & 77.77 & 103.55 & 237.93 & 5.49 & 2.41 & 331.83 & 2.00 \\
\hline S.D. & 0.69 & 1.65 & 1.15 & 0.09 & 0.04 & 1.94 & 0.14 \\
\hline Max & 79.20 & 105.30 & 241.00 & 5.70 & 2.50 & 333.50 & 2.10 \\
\hline Min & 76.90 & 101.40 & 236.10 & 5.30 & 2.30 & 329.70 & 1.90 \\
\hline Difference & 2.30 & 3.90 & 4.90 & 0.40 & 0.20 & 3.80 & 0.20 \\
\hline $99 \%$ Low & 75.69 & 98.60 & 234.49 & 5.20 & 2.29 & 326.01 & 1.58 \\
\hline 99\% High & 79.85 & 108.50 & 241.37 & 5.77 & 2.52 & 337.66 & 2.42 \\
\hline count & 26 & 4 & 27 & 14 & 20 & 3 & 2 \\
\hline
\end{tabular}




\begin{tabular}{|c|c|c|c|c|c|c|c|}
\hline & $\begin{array}{l}\text { Nylon } \\
\text { Weight } \\
\text { (g) }\end{array}$ & $\begin{array}{l}\text { Nylon } \\
\text { Length } \\
\text { (inches) }\end{array}$ & $\begin{array}{l}\text { Nylon } \\
\mathrm{g} / \text { inch }\end{array}$ & $\begin{array}{l}\text { Nylon Bag } \\
\text { Length } \\
\text { (inches) }\end{array}$ & $\begin{array}{c}\text { Nylon } \\
\text { g/inch } \\
\text { used }\end{array}$ & $\begin{array}{c}\text { Nylon } \\
\text { g/inch } \\
\text { used }\end{array}$ & $\begin{array}{l}\text { Nylon Bag } \\
\text { Weight }(\mathrm{g})\end{array}$ \\
\hline & 17.7 & $324 / 8$ & 0.54 & 7.5 & Max & 0.61 & 4.58 \\
\hline & 23.2 & 38 & 0.61 & 7.5 & Min & 0.54 & 4.08 \\
\hline & 11.3 & $196 / 8$ & 0.57 & 10 & Max & 0.61 & 6.11 \\
\hline & 13.9 & $237 / 8$ & 0.58 & 10 & Min & 0.54 & 5.45 \\
\hline Average & & & 0.58 & & & & 5.05 \\
\hline S.D. & & & 0.03 & & & & 0.90 \\
\hline Max & & & 0.61 & & & & 6.11 \\
\hline Min & & & 0.54 & & & & 4.08 \\
\hline Difference & & & 0.07 & & & & 2.02 \\
\hline 99\% Low & & & 0.50 & & & & 2.36 \\
\hline 99\% High & & & 0.66 & & & & 7.75 \\
\hline Count & & & 4 & & & & 4 \\
\hline
\end{tabular}

\begin{tabular}{|c|c|c|c|c|c|c|c|c|}
\hline $\begin{array}{c}\text { Packaging } \\
\# 1\end{array}$ & Min & Max & $\begin{array}{c}\text { Packaging } \\
\# 2\end{array}$ & Min & Max & $\begin{array}{c}\text { Packaging } \\
\# 3\end{array}$ & Min & Max \\
\hline Paint Pint & 75.69 & 79.85 & Paint Pint & 75.69 & 79.85 & Sealed Quart & 98.60 & 108.50 \\
\hline Nylon & 2.36 & 7.75 & Nylon & 2.36 & 7.75 & Nylon & 2.36 & 7.75 \\
\hline Nylon & 2.36 & 7.75 & Nylon & 2.36 & 7.75 & Nylon & 2.36 & 7.75 \\
\hline Sealed Quart & 98.60 & 108.50 & Sealed Juice & 234.49 & 241.37 & Sealed Juice & 234.49 & 241.37 \\
\hline Label & 5.20 & 5.77 & Label & 5.20 & 5.77 & Label & 5.20 & 5.77 \\
\hline Tie Wrap 1 & 2.29 & 2.52 & Tie Wrap 1 & 2.29 & 2.52 & Tie Wrap 1 & 2.29 & 2.52 \\
\hline Tie Wrap 2 & 2.29 & 2.52 & Tie Wrap 2 & 2.29 & 2.52 & Tie Wrap 2 & 2.29 & 2.52 \\
\hline Total & 188.78 & 214.67 & Total & 324.67 & 347.53 & Total & 347.58 & 376.19 \\
\hline Delta & 25.89 & & Delta & 22.86 & & Delta & 28.61 & \\
\hline Gallon Can & 326.01 & 337.66 & Gallon Can & 326.01 & 337.66 & Gallon Can & 326.01 & 337.66 \\
\hline TIDs & 1.58 & 2.42 & TIDs & 1.58 & 2.42 & TIDs & 1.58 & 2.42 \\
\hline Total & 516.36 & 554.75 & Total & 652.25 & 687.62 & Total & 675.16 & 716.27 \\
\hline Delta & 38.39 & & Delta & 35.37 & & Delta & 41.11 & \\
\hline
\end{tabular}

